VIII ${ }^{\text {ème }}$ Journées Génie Civil - Génie Côtier, Compiègne, 7-9 septembre 2004

\title{
Innovations in coastal research and instrumentation.
}

\author{
Piet Hoekstra \\ Institute for Marine and Atmospheric Research (IMAU), \\ Faculty of Geosciences, Department of Physical Geography, \\ Utrecht University, Heidelberglaan 2, 3508 TC Utrecht, the Netherlands \\ E-mail : p.hoekstra@geog.uu.nl
}

\begin{abstract}
Résumé
De nos jours, l'étude de morphodynamique côtière est une étude dynamique qui implique un couplage entre les systèmes de mesures de données côtières, les études de processus issues des simulations en laboratoire et expérimentations in situ, les études de modélisation numérique ainsi que les techniques liées à l'intégration de données et modélisations; ce couplage améliore notre compréhension des systèmes côtiers et nous permet de prévoir leur évolution. Les innovations issues de la recherche côtière et des systèmes de mesures de données interagissent fortement et se stimulent l'un et l'autre. Cette publication présente trois différents exemples (ADCP, le trépied HSM et le système vidéo ARGUS) d'innovations technologiques actuellement appliquées aux mesures de données et aux études de recherche côtière.
\end{abstract}

\section{Abstract:}

The present-day study of coastal morphodynamics involves a dynamic field of research in which combinations of coastal monitoring, process-oriented laboratory and field work, modelling studies and Data-Model Integration techniques enhance our capabilities to understand and predict coastal systems and their evolution. Innovations in coastal research and coastal instrumentation strongly interact and stimulate each other. This paper will give three different examples (ADCP, HSM frame and ARGUS video system) of technological innovations presently applied in coastal monitoring and research.

\section{Introduction}

In the past decades the study of coastal morphodynamics has rapidly evolved and is now a multidisciplinary science with contributions from coastal and marine geology, coastal oceanography, physical geography, civil and coastal engineering and marine biology and ecology. In the late '70's and early ' 80 's of the last century the term "coastal morphodynamics" was introduced by coastal geomorphologists (Wright and Thom, 1977; see also Carter and Woodroffe, 1994). Whereas the term "coastal morphology" implies a more static description of the state of the coast, including aspects related to the geomorphology and the sedimentology of the system, the expression "coastal morphodynamics" is interpreted in a much more dynamic sense and is defined as the mutual interactions (and feedbacks) between hydrodynamics and coastal morphology by means of sediment transport processes. The study of coastal systems was no longer restricted to the morphological components of the system but also required knowledge on the nearshore wave- and current conditions and the associated sediment transport processes and patterns. In addition, later on biological and ecological processes became relevant as well to understand coastal change. This interdisciplinary development of coastal science has also been inspired by the complex nature of coastal (and societal) problems, the continuously increasing human impact in the coastal zone, the need for understanding vulnerable coastal (eco)systems and their sustainability and the present and anticipated effects of global change. In this definition global change not only includes aspects of overall climatic change, such as the anticipated changes in river discharges, the increase in 
sea level rise and potential changes in hydro-meteorological conditions (= storm conditions and wind and wave climate). As a matter of fact, global change also includes a human component, such as related to changes in sediment supply in river deltas due to deforestation in river basins and associated, increased rates of coastal deposition Likewise, the purpose of coastal measurements and observations has changed dramatically and data collection in the coastal zone now serves a range of objectives.

This paper will demonstrate that innovations in coastal research and coastal instrumentation strongly interact and stimulate each other. The study of present-day coastal morphodynamics involves a dynamic field of research in which combinations of coastal monitoring, process-oriented laboratory and field work, modelling studies and Data-Model Integration techniques enhance our capabilities to understand and predict coastal systems and their evolution. This paper will show how coastal science has evolved over time and how technological innovations have contributed to this development. Three different examples are given of technological innovations presently applied in coastal monitoring and research.

\section{Coastal measurements and observations}

\subsection{Objectives of measurements}

Coastal zone measurements and observations were traditionally carried out to monitor the state of the coastal system and to record changes. However, the increased interest in (nearshore) coastal processes and the first attempts to simulate and predict coastal morphology and evolution by means of numerical computer models initiated the implementation of large-scale field experiments to unravel the role of individual wave-, current and sediment transport processes. Data sets obtained were also required to run, calibrate and validate these models. More recently, we see a new development of Data-Model Integration techniques - with data assimilation procedures - to overcome the present limitations of both field measurements and modelling efforts. To understand and predict coastal change on a time scale of 4 to 5 decades (or even more) is presently still beyond our scientific capabilities within the field of coastal research. Unfortunately, many coastal engineering, socio-economic and planning issues in the coastal zone have in common that they require a research approach that is able to cover these large temporal and spatial scales. Engineering works, for example, are typically designed for a period of about 40 to 50 years.

\subsection{Monitoring networks and routine measurements}

In the past coastal monitoring strategies and networks strongly focused on determining relatively simple morphological and hydrodynamical parameters in order to characterize the state of the coastal system. Morphological measurements are often carried out to monitor the cross-shore coastal profile to establish the monthly, seasonal or annual position of the coastline (or equivalent parameters such as the low water line, high tide mark or dune foot ), the overall change of the cross-shore coastal profile and the amounts of sediment involved. In the Netherlands, for example, the JARKUS monitoring system is operational since 1965 and cross-shore transects are measured annually until a depth of about 6-7 m offshore and with a longshore spacing of $200 \mathrm{~m}$. Unfortunately, these monitoring networks require substantial investments whereas the benefits commonly become obvious only after a period of years to decades. This type of monitoring though is still very important to evaluate the impact of individual storms, the more gradual process of sea level rise and the effect of coastal constructions on the shoreline. In the Netherlands these long term records also play a vital role in mitigating coastal erosion and are used for the design and implementation of beach and shoreface nourishments. Innovations may reduce the costs of these measurements and include, for example, the use of airborne laser altimetry to measure the dry part of the coastal 
profile, replacing conventional levelling or aerial photogrammetry. In the Netherlands an amphibious vehicle, the WESP (Water En Strand Profiler) was built for measuring coastal profiles (by DGPS), for taking samples and for deploying and servicing monitoring equipment.

In addition, hydrodynamic information in the coastal zone is often collected by means of standard monitoring networks consisting of tide gauges, wave buoys and, occasionally, measuring stations with current meters. In the last decades, the morphological and hydrodynamical monitoring has also been extended to include

ecologically relevant parameters such as water temperature, salinity, concentration

of suspended matter (SPM) and the amount of nutrients and/or pollutants. This

can be done on a routine basis or may be part of individual projects, e.g. as part of environmentally friendly dredging activities when on-line information is required on turbidity levels, SPM and current velocities.

One of the recent innovations in instrumentation is the multi-purpose use of acoustic devices for monitoring coastal processes and parameters. The use of Acoustic Doppler Current Profilers (ADCP) may serve as an example to illustrate this development.

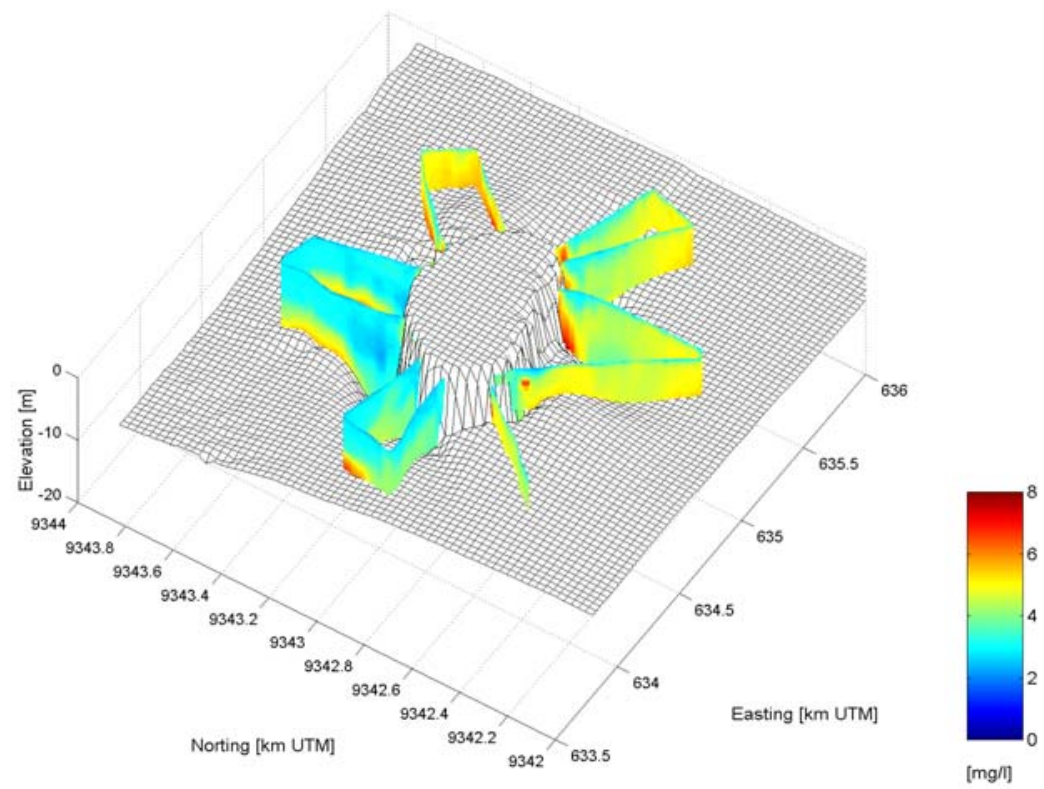

Figure 1: Turbidity patterns (Suspended Matter - SPM) around a coral reef in the Bay of Banten, Indonesia. The turbidity measurements are based on backscatter recordings of a $1200 \mathrm{kHz}$ ADCP (Hoitink, 2003).

Innovations in technology Example 1: Use of Acoustic Doppler Current Profiler (ADCP)

The ADCP was originally developed as an instrument to measure currents and vertical velocity profiles by means of the Doppler principle. Moving suspended particles in the water column create a frequency-shift of the transmitted ultra-sound waves of the instrument that is a measure for the flow velocity. The instrument is either mounted on a ship (measuring from surface to bottom) or is deployed at the seabed. More recenly though other applications have become available and the acoustic backscatter of the signals can also be used to determine the concentrations of SPM (Hoitink, 2003). By measuring the echo intensity of the ADCP signals and comparing these with Optical Backscatter (OBS) measurements that have been calibrated 
with in-situ water samples, the ADCP signals can be converted into suspended sediment concentration (SSC). These calibrations though may be both spatially and seasonally variable and depend, for example on the acoustic properties of the particles such as the grain size. Therefore, although the quantitative estimates may still be somewhat inaccurate,

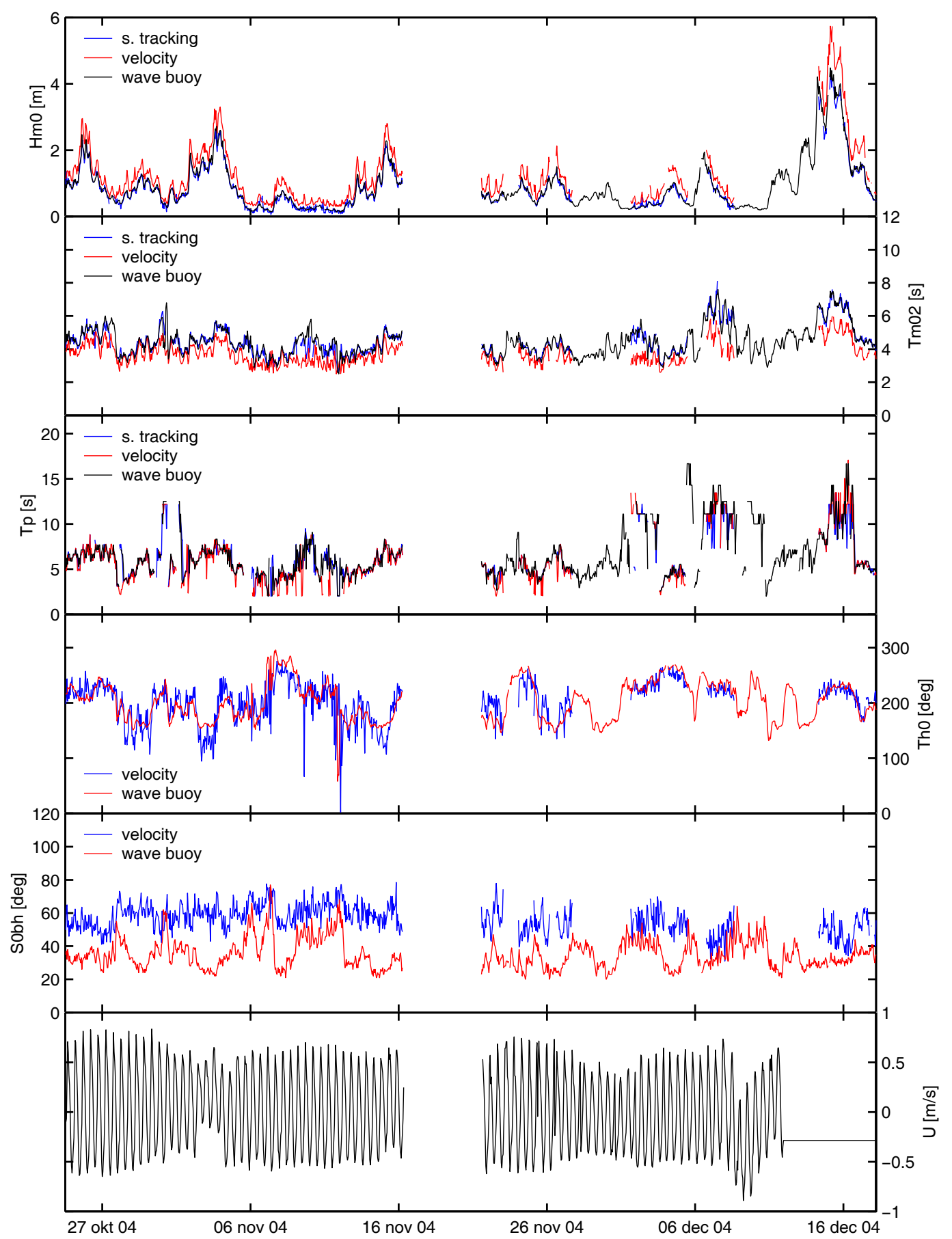

Figure 2: Time series of spectral domain parameters derived from surface tracking and current measurements with a $1200 \mathrm{kHz} A D C P$ and a wave buoy in water depths of about $11 \mathrm{~m}$ near the coast of Noordwijk aan Zee, Netherlands (in the bottom panel, U denotes the depth-mean, burst-averaged current component along the principal tidal axis ; Hoitink et al., 2004) 
The instrument is a powerful tool to detect temporal and spatial turbidity patterns. Hoitink (2003) applied this method in tropical waters in Indonesia to record the spatial distribution of SPM around a coral reef system (see Fig. 1). Dredging companies already start using this technology in order to produce a quick-scan of turbidity levels and patterns, especially in ecologically vulnerable coastal areas.

A third application of the ADCP is the use as a wave measuring device to determine directional wave spectra and associated wave parameters such as wave height, period and direction. For this purpose either the surface-tracking capability of the ADCP or the (waveinduced) velocity measurements can be used; both methods can also be applied in combination with a conventional pressure sensor (Strong et al, 2003). The surface-tracking mode is based on the principle that a bottom-mounted and upward-facing ADCP, after correction for geometric spreading and sound attenuation, will record the largest echointensity peak at the sea-air interface; in other words and in case of waves: the undulating water surface. Use of the velocity signals is an indirect method and a linear or non-linear wave model is always needed to convert current velocities to surface elevation. Figure 2 demonstrates a comparison between wave information derived from a directional wave buoy (Datawell) and an ADCP, during test measurements on the Dutch shoreface for a mean water depth of about $11 \mathrm{~m}$ (Hoitink, 2004).

Although both the second and third application still need further research, including systematic benchmarking tests, it is clear that in the near future ADCP's can be applied for different purposes. Having on-line information on waves and currents is not only relevant for monitoring issues, but will also be an attractive option for navigational purposes near ports.

\subsection{Identification of coastal processes}

The increased interest in (nearshore) coastal processes since the 70's and

80 's of the last century is explained by scientific curiosity, the urgent need for more quantitative approaches and is also related to the first attempts to simulate and predict coastal morphodynamics by means of numerical computer models. Results from theoretical and laboratory studies were used to develop mathematical models describing the water motion and sediment transport in the coastal zone. These models proved to be essential tools in predicting coastal change. However, with time scepsis grew about the performance of these models and coastal researchers began to realize that there existed a growing gap between the computational skills of these models and our actual knowledge on coastal processes, incorporated within these models. So far, only limited field studies were carried out (e.g.DUCK94 and Sandy Duck; see Birkemeier and Thornton, 1994) to unravel the current-, wave- and sediment transport processes and only part of this information was included in the models. In many cases, the computer models were still very simplified and schematised representations of the real world phenomena; therefore the qualitative and quantitative results of these models often became doubtful.

The existence of a significant gap between the actual knowledge on coastal processes and the computational skills of numerical models lead to a reappraisal of the use of field and laboratory investigations to understand coastal processes. Similar trends were observed in other fields of science. Progress in oceanography, for example, was hampered by the fact that modelling and remote sensing tools had become available since the seventies, substantially increasing the frequency, coverage and amount of data available. Meanwhile, however, this trend was accompanied by a reduction in the amount of ship-based observation stations and buoys which eventually turned out to be a major bottle neck in interpreting the remote sensing information and modelling results. 
Field and laboratory experiments again play a vital role in studying coastal morphodynamics. For example, the physics of sediment (sand) transport is still only partly understood and the present mathematical formulations largely depend on empirical information derived from the field or laboratory experiments (see e.g. Davies et al., 2002). Several sediment transport issues that still need to be solved are: 1) the relation between irregular waves and the concentration as well as the transport of SPM, 2) the sediment transport processes in the zone of breaking waves, 3) the role of bedload transport processes in various parts of the coastal system, 4) the effect of bedforms and biological activity in the benthic boundary layer on sediment resuspension and 5) the effect of sand-mud mixtures on coastal development. In recent years slow but steady progress has been made to measure a number of these effects.

The need to measure coastal processes in a more detailed way in the field has also resulted in a "technology push" to develop more advanced and less intrusive measuring instruments for processes operating in the nearshore zone. These include mechanical, electrical, optical and acoustic measuring devices. Likewise, this technological development has resulted in new scientific results that would not have been obtained otherwise with "traditional equipment". The development of the so-called HSM tripod by the Department of Physical Geography (Faculty of Geosciences, Utrecht University) is an exponent of this development.

\section{Innovations in technology Example 2: Sediment Transport Measurements with the HSM} tripod

HSM is an acronym for Hydrodynamics, Sediment transport and Micro-Morphology and is a stand-alone computerized tripod that can be placed on the seabed to measure current and intra-wave suspended sand transport processes in both fair weather and storm conditions (Fig. 3 ). The innovative instrument measures the wave height, current velocity, sand concentrations and bed form dimensions in water depths of about 4 to $20 \mathrm{~m}$. The instrument is able to determine the depth-integrated suspended sediment fluxes close to the bed. The sand transport is measured with an Acoustic Sand Transport Meter (ASTM). This measuring device again makes use of acoustic principles: the scattering and attenuation of ultra-sound waves by suspended sand particles. The velocity and concentration of moving suspended particles are simultaneously and continuously determined from the frequency shift and the amplitude of the scattered signals. In addition, the HSM tripod is equiped with a range of other instruments, including: 1) 6-7 Electro Magnetic Flow (EMF) meters to determine the near-bed velocity

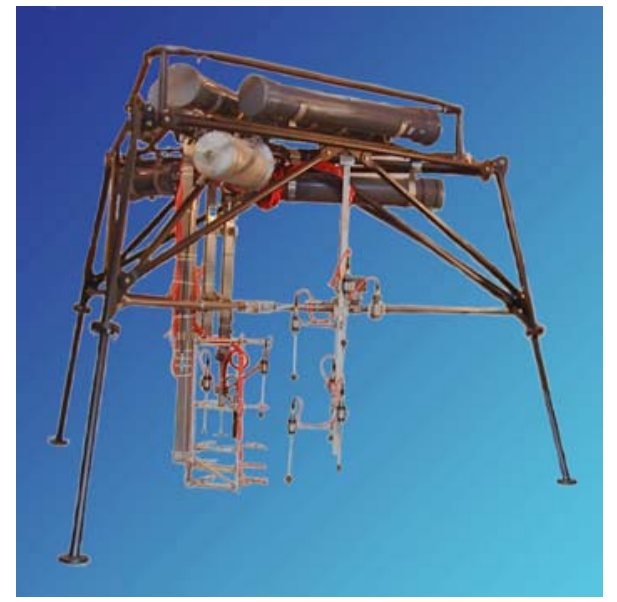

Figure 3: The HSM tripod to measure near-bed sand transport processes during fair weather and storm conditions. 
Profiles (shear stresses), 2) an Optical Backscatter (OBS) array to measure near-bed concentrations of SPM, 3) a robot-arm which automatically adjusts the OBS array at a fixed position relative to the bed (to account for changes in bed level due to the presence and migration of bedforms), 4) a ripple profiler to scan the sea bed and 5) altimeters to determine the position of the individual sensors relative to the bed. As one can notice there is another trend: the HSM tripod is developed in such a way that there is a certain redundancy in the collected information. First of all, this is done to reduce the risk of failure of individual sensors. Secondly though, the data sets are often not really identical but basically complementary. Due to the different technologies applied, inevitably the results will be different. For example, a sediment flux based on ASTM measurements is expected to differ from results based on the product of EMF and OBS measurements.

\section{Morphodynamic modelling: the use of data}

Ideally, coastal measurements and modelling should strongly interact to obtain reliable and realistic results on coastal behaviour. Coastal measurements can benefit from the existence of modelling tools to obtain information about the most critical and relevant processes operating within a coastal region. Subsequently, this information will be useful to define the proper type of measurements, the appropriate (or most critical) measuring positions and the measuring protocol, in terms of measuring frequency, intensity and length. In a number of cases models may also be necessary to unravel the individual role of coastal processes. The decomposition of a longshore current in the surfzone in wave-, wind- and tide-driven flow components requires an appropriate hydrodynamic model; measurements alone are insufficient.

a)Likewise - and vice versa - the relevance of coastal measurements for modelling coastal morphodynamics is easily supported by the following arguments :

b)Field measurements and laboratory experiments are essential to understand and improve our knowledge on coastal processes ;

Field measurements are used to establish boundary conditions for coastal modelling (e.g. to determine input values for wind, waves and tides) and to generate realistic hydrometeorological scenarios to predict future morphological changes ;

c)Morphodynamic models include a number of free model parameters that need specific (field) calibration and validation ;

d)Overall performance of a model has to be validated and tested with data sets.

The EU COAST3D project (1997-2001) is an example of a project in which the interactive approach of measurements and modelling was adopted (Soulsby, 2001 ; Van Rijn et al., 2002).

In the recent past different types of models have been developed to simulate and predict coastal development for a range of temporal and spatial scales. The most common models are the physical-deterministic models that operate in a time-dependent mode and are applied to predict coastal development on a scale of days to months or even years. However, these models tend to become less accurate on longer time scales and their results become questionable for a number of reasons. First of all, these models are based on our present knowledge of coastal processes and since this knowledge is far from perfect, these processbased numerical models suffer from the fact that the continuous time-loop executed in the model runs results in a propagation and multiplication of errors. Secondly, various free model parameters may be unknown, e.g. the roughness of the seabed in the presence of both currents and waves. And finally, for future predictions the forcing factors (and their sequences) are by definition unknown. Therefore, the predictive capability of these models is often limited. These models should actually be run in a stochastic environment to produce a 
probabilistic forecast that reflects the uncertainties in model parameters and forcing. This requires ensemble forecasting rather than the conventional method of producing one realisation of the future based on a previously defined input scenario related to anticipated hydro-meteorological conditions. Ensemble forecasting implies that a model is run repeatedly based on a probability density function of model parameters and various forcing parameterizations. This process may show that there appears to be a predictability horizon to coastal development (comparable to the existing uncertainties in weather forecasts); in other words after some time the predictability may have become so poor that the state of the system has really become unpredictable.

To avoid that situation and to be able to study large-scale coastal behaviour - coastal development on a spatial scale of tens of kilometres and on a temporal scale of decades - a range of behaviour-oriented models has been developed as well. These models are not based on a detailed description of physical processes but include processes at a much more aggregated level. Commonly, these models operate in a black box mode: a certain input generates a certain output based on empirical relations and generally without specifying the time scales of development and the way in which a new dynamic equilibrium is achieved. Nowadays, hybrid coastal models also exist and are a combination of process-based and behaviour-oriented models.

\section{Data-Model Integration techniques (DMI); Data Assimilation}

In the coming years Data-driven modelling and Data-Model Integration (DMI) will provide a good alternative and addition to the existing set of modelling and observation tools. DMI techniques require the use of data sets with both a high temporal and spatial resolution. Data sets that are nowadays available due to the use of new coastal remote sensing techniques such as the ARGUS automated video remote sensing system (Lippmann and Holman, 1989). The use of these techniques is very helpful in monitoring and recording rapid changes in coastal hydro- and morphodynamics. This can be illustrated by an example based on nearshore bar behaviour. Shore-parallel or shore-oblique nearshore bars are observed along many sandy coastlines in the world. They are important features of the coastal profile due to their effect on nearshore wave dissipation and the role in nearshore sediment budgets. These bars though appear to be highly dynamic features with changes in bar height, position, longshore shape (e.g varying from straight to undulating with rhythmic patterns) and crossshore migration, especially during high-energy events. The barred morphology is normally represented as a morphological perturbation relative to a time-averaged cross-shore profile. However, another way of approaching the problem of bar dynamics is by using a condensed measure of barred morphology, such as the time-dependent character of bar-crest lines. The position of these bar-crest lines can be observed by state-of-the-art video techniques.

\section{Innovations in technology Example 3: the use of ARGUS automated coastal video remote} sensing system.

The ARGUS system, presently operational at three sites along the Dutch coast, is part of an international network of observation stations that cover a variety of coastal environments. The ARGUS system produces long term data sets with a high temporal resolution; the system of 5 video-camera's covers a longshore distance of about 5-6 km and an offshore region of about 500-600 m. ARGUS images are commonly available for 10 minutes of every (daytime) hour. An example of these pictures is given in Fig. 4, showing both a snapshot and a timeaveraged exposure near Noordwijk aan Zee.

Time exposure images of breaker patterns based on ARGUS images were used to detect indirectly bar-crestlines during storm conditions during the COAST3D experiment near 
Egmond aan Zee, the Netherlands. This data set of bar-crestlines was merged with an existing data set based on DGPS surveys with the Dutch amphibious vehicle WESP (see section 2.2). The available ARGUS images were geometrically corrected to obtain plan views on a 2.5 by $2.5 \mathrm{~m}$ grid. Subsequently, an intensity-based crestline position $x_{i}(y)$ was computed by alongshore tracking of the intensity maximum across the bar region (Ruessink et al, 2000). However, merging of the WESP and ARGUS data of bar-crestlines was by no means a trivial affair, as the accuracy of the ARGUS information depends on a number of environmental conditions. In their paper, Van Enckevort and Ruessink (2001) analysed the time-varying offset of crestline position and concluded that
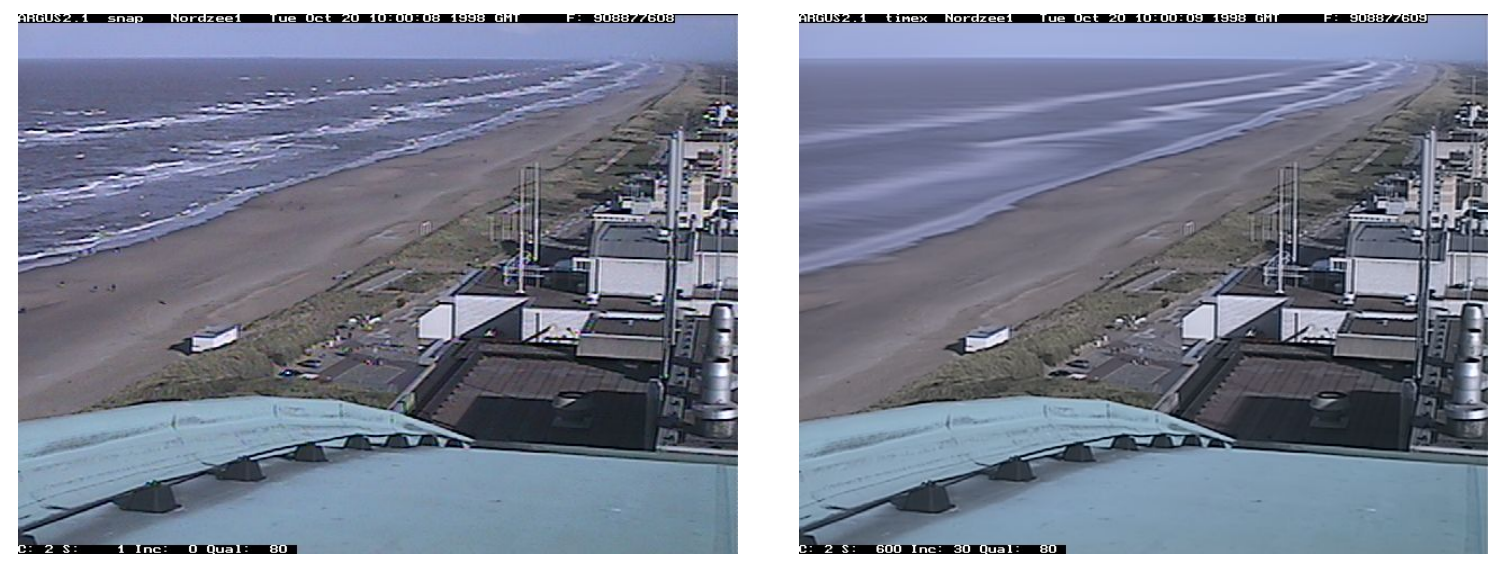

Figure 4: Snapshot and time exposure of the ARGUS video system, showing the beach and multiple bar system along the coast of Noordwijk, the Netherlands.

Intensity-based bar-crest positions $x_{i}$ differ from directly measured positions $x_{c}$ by a timevarying distance $\Delta x$, which is $\mathrm{O}(10 \mathrm{~m})$ and depends on wave height $H_{0}$, the water level $\eta_{0}$ and the bathymetry itself. The actual measured bar location tends to act as an outer bound to the extent of $x_{i}$; it implies that wave breaking is often taking place shoreward of the bar crest due to breaker delay and roller effects (Van Enckevort and Ruessink, 2001). The effect of the different environmental parameters on $\Delta x$ was investigated from simultaneous video observations and bathymetric surveys, collected during the Coast3 $\mathrm{D}$ experiment and from wave-model predictions, assuming that the roller energy represents intensity. Under nonsaturated conditions, the offset $\Delta x$ was about equally affected by a change in wave height and water depth. However, under saturated conditions, only the water level $\left(\eta_{0}\right)$ dependence remained. As a result, for the inner bar the error in $x_{i}$ - compared to the actual value $x_{c}$ - is mainly due to $\eta_{0}$. (Van Enckevort and Ruessink, 2001). This knowledge was used to correct for the offsets.

To correct for the offsets two different methods were applied: Kingston et al. (2000) developed an Artificial Neural Network (ANN) for the inner and outer bars and Van Enckevort and Ruessink (2001) developed an empirical relation linking the offset of the inner bar crest position to (tidal) water levels $\left(\Delta x=f\left(\eta_{0}\right)\right.$. The purpose of the ANN approach is to "train the network such that the response to a given set of inputs corresponds as closely as possible to a desired output". The ANN methodology significantly reduced the offsets in bar crest position. For example, the residual error for the location of the outer bar was reduced to less than $5 \mathrm{~m}$; for the inner bar the residuals were reduced to $10 \mathrm{~m}$ or less.

Ruessink et al (2000), using the empirical relation developed by Van Enckevort and Ruessink (2001), could add another set of video-based bar-crest line estimates for the inner bar, corrected for the offset due to water levels. The merging of data sets finally resulted in a database with the following contents. The combined inner bar data set consisted of 30 crestlines (out of a total of 42 days): 20 were based on WESP surveys and the other 10 were a 
result of video estimates. For the outer bar the combined data set comprised 20 daily bar crest lines, 9 of which were based on direct bathymetric surveys and the remaining 11 are a product of the video estimates.

Finally, all individual crest line data was demeaned by subtracting the campaign average value of the inner and outer bar crest position $x_{\mathrm{c}}, y, t$ (for the inner and outer bar these values are 212 and $477 \mathrm{~m}$, respectively). Consequently, morphological changes in bar-crest position (and associated bar morphology) were given relative to its time-averaged mean position (over a period of 6 weeks) instead of a rather arbitrary and artificial boundary condition such as the onshore located baseline $\mathrm{x}=0$; the value is indicated by $u_{c, m}, y$.

The longshore and temporal variability of the (demeaned) bar-crest lines can now be expressed by two simple parameters (Ruessink et al, 2000): the longshore mean bar crest position $x_{c, m}$,y and the amplitude $A_{c}$ around the mean of each line. This amplitude is a horizontal and cross-shore amplitude and was defined as half the distance between the most seaward and shoreward perturbation along each line. Based on this analysis it was concluded that nearshore bar behaviour near Egmond aan Zee on a time scale of 6 weeks is not related to alongshore-uniform bar behaviour, but is determined by the development of threedimensional features. For the inner bar, the first part of the observational period was characterized by longshore shifts in crestlines; the second part of the campaign though hardly showed a longshore movement and the crest lines appeared to demonstrate an increase in amplitude.

This example of a morphodynamic study carried out during the EU COAST3D experiment demonstrates the powerful use of DMI techniques. By using a combination of state-of-the art observation technology (ARGUS video remote sensing and DGPS surveys by WESP), hydrodynamic modelling and (geo)statistical tools (the Artificial Neural Network that was applied is equivalent to a multivariate multiple non-linear regression model) data sets can be extended in both the temporal and spatial domain. This opens new opportunities for understanding and predicting coastal change on a range of scales.

\section{Concluding Remarks}

During the last two decades important progress has been achieved in improving monitoring networks, developing state-of-the-art technology for process-oriented measurements and computer models for coastal morphodynamics. Although technological advances play an important role their introduction is generally not without difficulty. The present use of many acoustic devices in coastal research, for example, frequently requires tremendous attempts to validate and calibrate the collected data sets. However, field calibration of this type of equipment is often hardly possible and logistically complicated.

Presently, the most promising development probably is the use of DMI techniques in coastal research and monitoring. As a matter of fact, the traditional boundaries between monitoring, process-oriented field measurements and modelling seem to disappear and DMI techniques will give added value to both the collection of field data and the operational use of models.

For further details on projects and instrumentation mentioned in this paper please visit the following web site: www.coastalresearch.nl

\section{References}

1.Birkemeier, W. and Thornton, E.B., 1994. The DUCK94 Nearshore Field Experiment. Proc. Coastal Dynamics '94, ASCE New York, 815-821.

2.Carter, R.W.G. and Woodroffe, C.D., 1994. Coastal Evolution. Late Quaternary shoreline morphodynamics. Cambridge Univ. Press, Cambridge, 517 pp. 
3.Davies, A.G., Van Rijn, L.C., Damgaard, J, Van de Graaff, J. and Ribberink, J.S., 2002. Intercomparison of research and practical sand transport models. Coastal Engineering 46, 123.

4.Enckevort, I.M.J. van, and Ruessink, B.G., 2001. Effect of hydrodynamics and bathymetry on video estimates of nearshore sandbar position. Journal of Geophysical Research 106, 16969-16980.

5.Hoitink, A.J.F., 2003. Physics of coral reef systems in a shallow tidal embayment. $\mathrm{PhD}$ thesis Utrecht University, Faculty of Geographical Sciences, $144 \mathrm{pp}$.

6.Hoitink, A.J.F., Ruessink, B.G. and Hoekstra, P., 2004. Intercomparison of wave parameters and spectra from $A D C P$ and wave buoy measurements. IMAU Utrecht University, report 04-02, 23 pp.

7.Kingston, K.S., Ruessink, B.G., Enckevort, I.M.J. van, and Davidson, M.A., 2000. Artificial neural network correction of remotely sensed sandbar location. Marine Geology $169,137-160$.

8.Lippmann, T.C. and Holman, R.A., 1989. Quantification of sand bar morphology: a video technique based on wave dissipation. Journal of Geophysical Research 94, 995-1011.

9.Ruessink, B.G., Enckevort, I.M.J. van, Kingston, K.S. and Davidson, M.A., 2000. Analysis of observed two- and three dimensional nearshore bar behaviour. Marine Geology $169,161-183$.

10.Soulsby, R.L., 2001. Sediment transport and Morphodynamics on complex coastlinesThe COAST3D project. In: Hanson, H. and Larson, M.(eds.), Coastal Dynamics '01, Lund, Sweden, ASCE, 92-101.

11.Strong, B., Brumley, B, Stone, G.W. and Zhang, X., 2003 The application of the Doppler shifted dispersion relationship to hurricane data from an ADCP directional wave gauge and co-located pressure sensor. Proc. IEEE/OES $7^{\text {th }}$ working conference on current measurement technology, pp. 119-125.

12.Van Rijn, L.C., Ruessink, B.G. and Mulder, J.P.M., 2002. COAST3D Egmond - The Behaviour of a straight sandy coast on the time scale of storms and seasons. EU-MAST 3 programme. Aqua Publications, Amsterdam.

13.Wright, L.D. and Thom, B.G., 1977. Coastal depositional landforms: a morphodynamic Approach. Progress in Physical Geography, 1, 412-459. 